\title{
Comparison of the effects of spinal epidural and general anesthesia on coagulation and fibrinolysis in laparoscopic cholecystectomy: a randomized controlled trial
}

\author{
Suleyman Demiryas ${ }^{1}$, Turgut Donmez ${ }^{2}$, Vuslat Muslu Erdem ${ }^{3}$, Duygu Ayfer Erdem ${ }^{3}$, Engin Hatipoglu ${ }^{1}$, \\ Sina Ferahman ${ }^{1}$, Oguzhan Sunamak ${ }^{4}$, Lale Yoldas Zengin ${ }^{5}$, Ahmet Kocakusak ${ }^{6}$ \\ ${ }^{1}$ Department of General Surgery, Istanbul Cerrahpasa Medicine Faculty, Istanbul, Turkey \\ ${ }^{2}$ Department of General Surgery, Lutfiye Nuri Burat State Hospital, Istanbul, Turkey \\ ${ }^{3}$ Department of Anesthesiology, Lutfiye Nuri Burat State Hospital, Istanbul, Turkey \\ ${ }^{4}$ Department of General Surgery, Haydarpaşa Numune Training and Research Hospital, Istanbul, Turkey \\ ${ }^{5}$ Department of Biochemistry, Lutfiye Nuri Burat State Hospital, Istanbul, Turkey \\ ${ }^{6}$ Department of General Surgery, Haseki Training and Research Hospital, Istanbul, Turkey
}

Videosurgery Miniinv 2017; 12 (3): 330-340 DOI: https://doi.org/10.5114/wiitm.2017.70249

\begin{abstract}
Introduction: Laparoscopic cholecystectomy (LC) is usually performed under general anesthesia. Recently, laparoscopic cholecystectomy under regional anesthesia has become popular, but this creates a serious risk of thromboembolism because of pneumoperitoneum, anesthesia technique, operative positioning, and patient-specific risk factors. Aim: This randomized controlled trial compares the effects of two different anesthesia techniques in laparoscopic cholecystectomy on coagulation and fibrinolysis.

Material and methods: This randomized prospective study included 60 low-risk patients with deep vein thrombosis (DVT) who underwent elective LC without thrombo-emboli prophylaxis. The patients were randomly divided into two groups according to the anesthesia technique: the general anesthesia (group 1, $n=30$ ) and spinal epidural anesthesia (group 2, $n=30$ ) groups. Measurement of the prothrombin time (PT), thrombin time (TT), international normalized ratio (INR), activated partial thromboplastin time (aPTT), and blood levels of D-dimer (DD) and fibrinogen (F) were recorded preoperatively (pre), at the first hour (post 1) and $24 \mathrm{~h}$ (post 24) after the surgery. These results were compared both between and within the groups.

Results: The mean age was $51.5 \pm 16.7$ years (range: 19-79 years). Pneumoperitoneum time was similar between group 1 (33.8 \pm 7.8$)$ and group $2(34.8 \pm 10.4)$. The TT levels significantly declined postoperatively in both groups. The levels of PT, aPTT, INR, D-dimer and fibrinogen dramatically increased postoperatively in both groups.

Conclusions: While there was not any DVT, there was a significant decline in TT. There was a dramatic rise in the PT, INR, D-dimer, fibrin degradation products (FDP), and fibrinogen following LC. This may be attributed to the effects of pneumoperitoneum and anesthesia techniques on portal vein flow.
\end{abstract}

Key words: general anesthesia, laparoscopic surgery, fibrinogen. 


\section{Introduction}

Laparoscopic cholecystectomy (LC) was performed by the French doctor Phillipe Mouret in 1987 for the first time. Since then, LC has become the gold standard for uncomplicated symptomatic cholelithiasis or gall bladder polyps [1-8]. Laparoscopic methods have less postoperative pain, pulmonary complications, and morbidity. They provide earlier oral intake, quicker mobilization, short hospitalization, and decreased overall costs $[6,7,9,10]$.

Laparoscopic cholecystectomy is mostly performed under general anesthesia (GA) $[4,5,7,9$, 11]. This helps minimize secondary aspiration, abdominal discomfort, and respiratory distress due to carbon dioxide pneumoperitoneum and hypercapnia $[4,5,12,13]$. Currently, spinal, epidural or combined spinal-epidural anesthesia (CSEA) can also be used in LC [5]. Previously, LC under regional anesthesia (RA) was carried out in a limited number of patients mostly in cases with chronic respiratory disease in whom general anesthesia was contraindicated [4, 7, $9,12]$. However, laparoscopic cholecystectomy under regional anesthesia has also become popular recently. Recent studies on spinal and epidural anesthesia in LC have confirmed the safety and availability of this procedure. Thoracic epidural anesthesia and GA can be combined in LC to provide more effective analgesia during the early postoperative period $[4,7,14]$. The RA demonstrates less postoperative pain and a smaller neuroendocrine stress response compared to GA $[15,16]$. However, abdominal discomfort and shoulder pain are the most frequent complaints $[4,5,12]$.

Parameters in the coagulation and fibrinolysis processes have been studied in terms of laparoscopic cholecystectomies, especially the prothrombin time (PT), the international normalized ratio (INR), the activated partial thromboplastin time (aPTT), and D-dimer and plasma fibrinogen levels $[17,18]$.

Asymptomatic patients hospitalized in general surgery clinics in whom thromboprophylaxis was not used had deep vein thrombosis (DVT) rates between 15 and $40 \%$; the rate was < $10 \%$ in patients with low risk and $40-80 \%$ in the high-risk group in terms of DVT [19]. Both mechanical and pharmacological DVT prophylaxis measures have been suggested in many studies $[2,3,20]$. However, some other reports have suggested that prophylaxis during LCs is unnecessary [17]. There are very few prospective stud- ies in the literature that evaluate the effect of the type of anesthesia on surgical procedure, fibrinolytic system, and homeostasis parameters. Deep venous thrombosis and emboli, although rare, are important causes of postoperative morbidity and mortality. There are numerous studies showing that intra-abdominal pressure due to pneumoperitoneum in laparoscopic surgery might affect coagulation and fibrinolysis mechanisms. Recently, many studies on regional anesthesia in laparoscopic cholecystectomy have been published. Regional anesthesia is known to result in peripheral vasodilatation.

\section{Aim}

Keeping the pressure of pneumoperitoneum low, we aimed to analyze the effect of anesthesia methods on coagulation and fibrinolysis.

\section{Material and methods}

Ethics committee approval (No. 222) and the written informed consent in accordance with the Helsinki Declaration were obtained. This study was assigned Clinical Trial Number NCT02568852. Seventy-six patients with the surgical indication of cholecystectomy due to cholelithiasis or gall bladder polyp were enrolled (see Figure 1 for flow diagram). All patients were diagnosed using hepatobiliary ultrasonography (USG) by the same radiologist. The patients' lower extremities were evaluated by color Doppler ultrasonography preoperatively and $24 \mathrm{~h}$ postoperatively.

Patients were divided into 2 groups: general anesthesia (group 1) and combined spinal/epidural anesthesia (CSEA; group 2). These were randomly assigned with a computer program. Anesthesia was performed by the same anesthetists. No patients received premedication. All patients were prepared for surgery by infusing an I.V. line and $10 \mathrm{ml} / \mathrm{kg}$ Ringer's lactate solution for $30 \mathrm{~min}$. In group 1, anesthesia was induced with propofol $(2-2.5 \mathrm{mg} / \mathrm{kg})$, fentanyl $1 \mu \mathrm{g} / \mathrm{kg}$ and rocuronium $0.6 \mathrm{mg} / \mathrm{kg}$ and the patients were intubated endotracheally. The patients were mechanically ventilated in controlled mode $(V t=6-8 \mathrm{ml} / \mathrm{kg})$. The frequency of respiration was set at $\mathrm{PETCO}_{2}$ 32-36 mm Hg. To maintain anesthesia, sevoflurane (1.5-2\%) with an oxygen-air mixture $\left(\mathrm{FiO}_{2}=0.4\right)$ was used; rocuronium $(0.015 \mathrm{mg} / \mathrm{kg})$ was administered at maintenance dosages. Residual neuromuscular blocking was antagonized with 


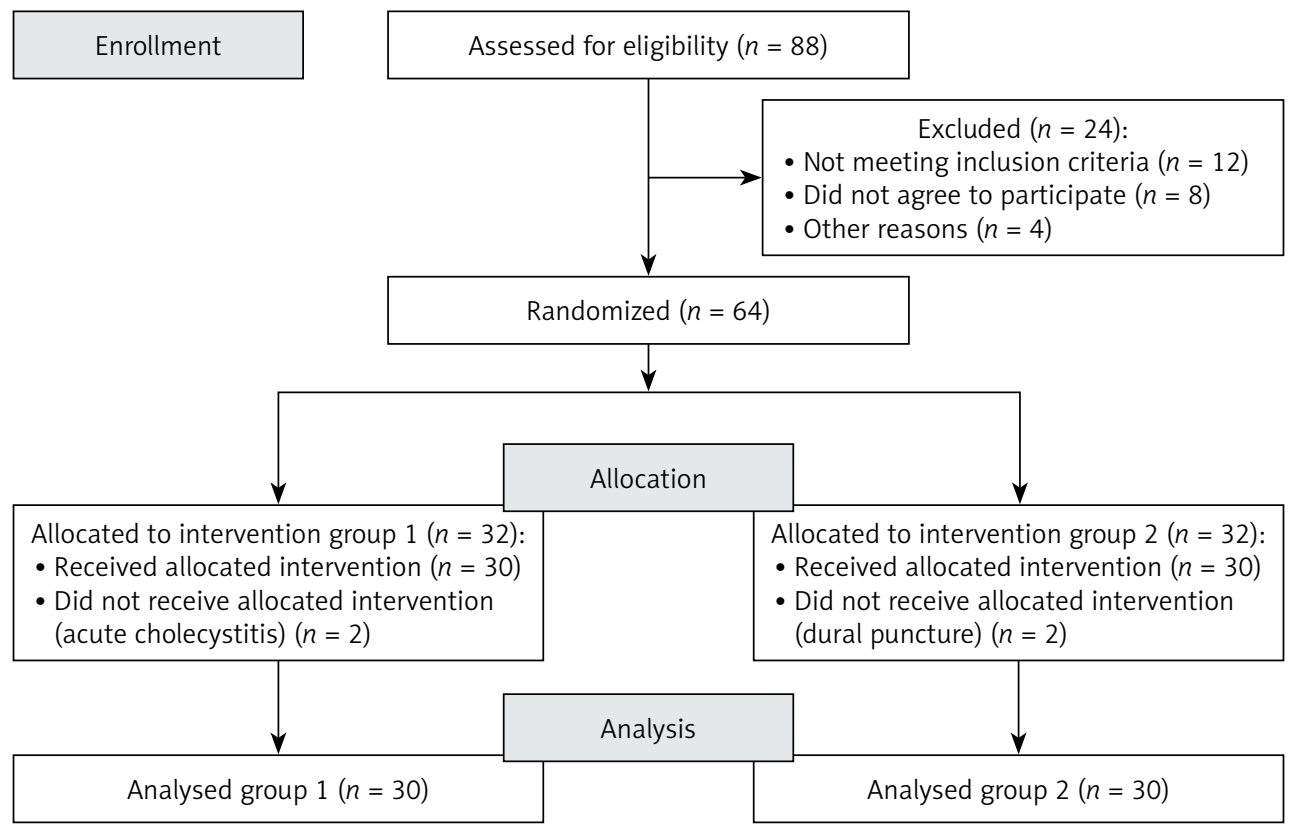

Figure 1. Flowchart diagram of the study

2-2.5 mg neostigmine and $1 \mathrm{mg}$ atropine at the end of the surgery.

In group 2, anesthesia used the needle-through-needle technique through the $\mathrm{L} 2-\mathrm{L} 3$ intervertebral space in a sitting position under sterile conditions. Intradermal lidocaine $1 \%$ was used for local anesthesia. A Tuohy $18-\mathrm{G}$ needle was inserted into the epidural space at the midline using the physiological saline loss of resistance technique. Then, a $26-G$ pencil point spinal needle was administered through the Tuohy needle to access the subarachnoid space. After observing free leakage of cerebrospinal fluid (CSF), hyperbaric bupivacaine $16 \mathrm{mg}$ and fentanyl $10 \mu \mathrm{g}$ were injected for $30 \mathrm{~s}$. The spinal needle was removed and a 20-G epidural catheter was inserted into the cephalad direction and fixed at $4 \mathrm{~cm}$ in the epidural space. Next, a $20 \mathrm{ml}$ mixture of $10 \mathrm{ml}$ bupivacaine $0.5 \%, 5 \mathrm{ml} 2 \%$ lidocaine, $1 \mathrm{ml}$ fentanyl, and $4 \mathrm{ml}$ isotonic saline were administered into the epidural space. Patients were positioned in the $15^{\circ}$ Trendelenburg position and sensory blockade was controlled using a pin-prick test at 1 min intervals. Surgery was initiated after completion of sensory blockade at the T4 level. If anesthesia could not proceed at an adequate level or patients could not tolerate pain, then the operation was converted to open surgery with general anesthesia. Midazolam $0.015 \mathrm{mg} / \mathrm{kg}$ and fentanyl 1-2 $\mu \mathrm{g} / \mathrm{kg}$ were used for anxiety and for shoulder pain, respectively, during the operation.
All LCs were performed by the same general surgeons at $10 \mathrm{~mm} \mathrm{Hg} \mathrm{CO}$ pneumoperitoneum pressure. The Veress needle was used for the first entry with a 30-degree camera angle; four standard port sites were used for the operation.

We compared the coagulation and fibrinolysis parameters (CFP) in both groups. To assess both coagulation and fibrinolysis, we used the PT, aPTT, thrombin time (TT), INR, fibrinogen, and D-dimer levels of the venous blood samples collected on the morning of the procedure and 1 and $24 \mathrm{~h}$ after surgery. Blood samples were analyzed via an automatic coagulation analyzer (Diagnostica Stago, STA Compact, France) as well as an STA Neoplastine $\mathrm{Cl}$ plus kit for PT and INR (normal levels: 12-15 s and 0.9$1.2 \mathrm{~s}$ ), STA and PTT A 5 kit for aPTT (normal levels: 28-40 s), STA fibrinogen 5 kit for fibrinogen (normal levels: $200-400 \mathrm{mg} / \mathrm{dl}$ ), and STA Liatest D-DI kit for D-dimer (normal $<0.5 \mathrm{mg} / \mathrm{l}$ ).

The exclusion criteria were acute cholecystitis, acute pancreatitis, cholangitis, main biliary duct stone, contraindications for spinal anesthesia, pneumoperitoneum, dural puncture, uncooperative patients, psychiatric disease, hemorrhagic diathesis, age lower than 18, American Society of Anesthesiologists (ASA) physiology state > III, upper abdominal surgery history, and pregnancy.

Prophylactic low molecular weight heparin (LMWH) was not used, but deep venous thrombosis 
was prevented with elastic socks in all patients preoperatively.

\section{Statistical analysis}

For statistical analysis, SPSS 15.0 for Windows was used. For descriptive statistics and categorical variables, we used number and percentage. For numerical variables, the mean, standard deviation, minimum, and maximum were used. Student's $t$-test was used in conditions where numerical variables were distributed equally between the groups; the Mann-Whitney $U$ test was used for dissimilar distributions. Comparison of more than two dependent groups was done via repetitive measurement variance analysis when the variables were distributed normally and with the Friedman test when the variables were not normally distributed. Subgroup analysis was performed with the Wilcoxon test and eval- uated by Bonferroni correction. A $\chi^{2}$ test was used to analyze the ratio of categorical variables between the groups, and the results were evaluated with a Bonferroni correction when conditions were not ensured. Power analysis with $\alpha=0.05$ and $\beta=0.2$ for determining the $15 \%$ reduction on the $D$-dimer level with $10 \mathrm{~mm} \mathrm{Hg}$ pressure of pneumoperitoneum revealed that each group required a minimum of 24 patients. We adopted a value of $p<0.05$ as being statistically significant.

\section{Results}

Laparoscopic cholecystectomy was successfully performed in all cases with neither intraoperative complications nor a necessity for conversion to open surgery. The general features of the groups are summarized and listed in Table I. All patients had an uneventful postoperative course without any com-

Table I. Characteristics of the patients

\begin{tabular}{|c|c|c|c|c|}
\hline Parameter & & GA group & CSEA group & $P$-value \\
\hline Gender, $n(\%)$ & $F / M$ & $21(70.0) / 9(30.0)$ & $19(63.3) / 11(36.7)$ & 0.584 \\
\hline ASA, $n(\%)$ & $|/||/|||$ & $15(50.0) / 14(46.7) / 1(3.3)$ & $16(53.3) / 11(37.7) / 3(10)$ & 0.526 \\
\hline Drain usage, $n(\%)$ & & $6(20.0)$ & $4(13.3)$ & 0.488 \\
\hline Complication, $n(\%)$ & & $1(3.3)$ & $1(3.3)$ & 1.000 \\
\hline \multirow[t]{7}{*}{ Concomitant disease, $n(\%)$ : } & & $16(53.3)$ & $12(40)$ & 0.777 \\
\hline & Hypertension & $6(20)$ & $7(23.3)$ & 0.754 \\
\hline & Diabetes mellitus & $7(23.3)$ & $7(23.3)$ & 1.000 \\
\hline & COPD & $3(10)$ & $5(16.7)$ & 0.706 \\
\hline & Asthma & $2(6.7)$ & $0(0.0)$ & 0.492 \\
\hline & $\begin{array}{c}\text { Ischaemic cardiac } \\
\text { disease }\end{array}$ & $2(6.7)$ & $0(0.0)$ & 0.492 \\
\hline & Other diseases & $2(6.7)$ & $0(0.0)$ & 0.492 \\
\hline $\begin{array}{l}\text { Age, mean } \pm \text { SD } \\
\text { (min.-max.) [years] }\end{array}$ & & $50.7 \pm 16.2(19-77)$ & $52.4 \pm 17.6(22-79)$ & 0.723 \\
\hline $\begin{array}{l}\text { BMI, mean } \pm \mathrm{SD} \\
(\text { min. }- \text { max. })\left[\mathrm{kg} / \mathrm{cm}^{2}\right]\end{array}$ & & $27.2 \pm 4.4(19.7-34.6)$ & $27.1 \pm 4.3(17.8-33.9)$ & 0.824 \\
\hline $\begin{array}{l}\text { Total surgery time, mean } \\
\pm \mathrm{SD}(\min .-\max .)[\mathrm{min}]\end{array}$ & & $53.6 \pm 8.7(45-80)$ & $63.9 \pm 10.2(53-92)$ & $<0.001$ \\
\hline $\begin{array}{l}\text { Pneumoperitoneum time, } \\
\text { mean } \pm \text { SD (min.-max.) } \\
\text { [min] }\end{array}$ & & $33.8 \pm 7.8(25-60)$ & $34.8 \pm 10.4(25-65)$ & 0.666 \\
\hline $\begin{array}{l}\text { Oral intake, mean } \pm \text { SD } \\
\text { (min.-max.) }[\mathrm{h}]\end{array}$ & & $8.5 \pm 0.7(8-10)$ & $8.4 \pm 0.6(8-10)$ & 0.964 \\
\hline
\end{tabular}

$M$ - male, F-female, BMI - body mass index, ASA - American Society of Anesthesiologists, COPD - chronic obstructive pulmonary disease. 
plications or death. The patients were discharged between the postoperative (postop) $26^{\text {th }}$ and $48^{\text {th }} \mathrm{h}$. No clinically evident DVT was observed.

There was no significant difference between the groups in terms of demographic characteristics, ASA classification, coexisting disease (hypertension, diabetes mellitus and chronic obstructive pulmonary disease), drain usage, surgical complications, pneumoperitoneum time or oral intake time (Table I). The total time of surgical intervention was $53.6 \pm 8.7$ (45-80) min in group 1 and $63.9 \pm 10.2(53-92) \mathrm{min}$ in group 2. The total time of surgical intervention in group 2 was significantly longer than in group 1 $(p<0.001)$. There was no statistically significant difference between groups in the mean preoperative (Preop) PT values.

The mean postoperative $1^{\text {st }}$ and $24^{\text {th }} \mathrm{h}$ PT values of group 2 were significantly higher than those of group 1 (Table II, Figure 2).

There was no significant difference within group 1 in terms of PT values of preoperative and postoperative 1-hour measurements (Figure 2). The increases were statistically significant at 1 and $24 \mathrm{~h}$ compared to the baseline values in group 2 (Table III).

The mean aPTT in group 2 was significantly higher than that of group 1 at the postop $1^{\text {st }}$ and $24^{\text {th }} \mathrm{h}$ (Table II, Figure 3). There was no statistically significant difference between the preop and postop $1^{\text {st }} h$ values within group 2 (Table III).

There was no statistically significant difference between the groups in mean TT values, but there were statistically significant differences between preop vs. postop TT values in both groups (Table II vs. III, Figure 4).

The changes within both groups were statistically significant for the INR ( $p<0.001$ for each). The increases within both groups were statistically significant. There was no difference in the mean pre INR values between the groups $(p=0.203)$. The mean postop $1 \mathrm{~h}$ and postop $24 \mathrm{~h}$ INR values in the CSEA group were significantly higher than those of the GA group ( $p<0.001$ for each) (Table II vs. III) (Figure 3).

The mean fibrinogen $(F)$ value was significantly higher in group 2 compared to group 1 (Table II). Also, there were significant differences between preop vs. postop $F$ values in both groups (Table III, Figure 5).

There was no statistically significant difference between the groups in terms of mean preop D-dimer values (Table II). The mean D-dimer values at the $1^{\text {st }}$ and the $24^{\text {th }}$ postop $h$ in group 2 were significantly higher than those in group 1 (Tables II and III). Also, there were significant differences between preop vs. postop D-dimer values in both groups (Figure 6).

\section{Discussion}

Laparoscopic cholecystectomy causes hemodynamic changes in both the inferior vena cava and femoral veins leading to venous stasis in the lower extremities. This can result in undesired activation of coagulation and hypercoagulability [8]. Many factors such as the surgical technique (either open or laparoscopic), increased intra-abdominal pressure caused by pneumoperitoneum, medicaments (anesthetics, analgesics, antibiotics, etc.) and anesthetic technique can lead to postoperative hypercoagulability. Hypercoagulability can result in thromboemboli in addition to DVT. The development of DVT is attributed to venous stasis, abnormal activation of blood coagulation, and endothelial damage (Virchow's triad) [3, 19-21]. The stress response, pain, and inflammation induced by surgery lead to hypercoagulability and promote postoperative DVT. The surgical position and postoperative immobilization also promote DVT, resulting in venous stasis.

$\mathrm{CO}_{2}$ insufflation is the most common approach to obtain pneumoperitoneum (PP). Nowadays an intra-abdominal pressure of $12 \mathrm{~mm} \mathrm{Hg}$ is commonly employed [10, 22, 23]. Amir et al. reported that the pressure generated by conditions such as $\mathrm{CO}_{2} \mathrm{PP}$ caused liver injury in a rat study. The injury reported caused by $\geq 15 \mathrm{~mm} \mathrm{Hg}$ was no longer reversible if it had been applied for more than 60 min [24]. Wazz et al. found no significant difference in preoperative and postoperative values of aPTT, INR vs. fibrinogen under $12 \mathrm{~mm} \mathrm{Hg}$ pressure (65 LC patients) [25].

Many factors affect liver blood flow (LBF), including intermittent positive pressure ventilation, blood gas changes, sympathetic nervous system activity, splanchnic reflexes, fluctuations in cardiac output, hepatogastrointestinal diseases, direct effects of many anesthetics and other drugs, and the surgical trauma itself. Anesthetic agents and techniques such as spinal or epidural decrease the LBF. The LBF is also decreased by lower cardiac output due to myocardial depression, increased splanchnic vascular resistance due to catecholamine stimulation, and in the case of spinal and epidural anesthesia a decrease in the mean arterial blood pressure. No deteriorating effects were seen in patients 
Table II. Comparison of laboratory values between GA and CSEA groups - I

\begin{tabular}{|c|c|c|c|c|c|}
\hline \multirow[t]{2}{*}{ Parameter } & \multicolumn{2}{|c|}{ GA group $(n=30)$} & \multicolumn{2}{|c|}{ CSEA group $(n=30)$} & \multirow[t]{2}{*}{$P$-value } \\
\hline & Mean \pm SD & Median & Mean \pm SD & Median & \\
\hline \multicolumn{6}{|l|}{ PT: } \\
\hline Pre & $11.84 \pm 0.63$ & 11.7 & $11.82 \pm 0.71$ & 11.9 & 0.909 \\
\hline Post 1 & $12.01 \pm 0.52$ & 12.0 & $12.68 \pm 0.77$ & 12.6 & $<0.001$ \\
\hline Post 24 & $12.36 \pm 0.80$ & 12.3 & $13.63 \pm 0.99$ & 13.6 & $<0.001$ \\
\hline$P$-value & \multicolumn{2}{|c|}{$<0.001$} & \multicolumn{2}{|c|}{$<0.001$} & \\
\hline \multicolumn{6}{|l|}{ APTT: } \\
\hline Pre & $24.10 \pm 3.27$ & 23.1 & $24.97 \pm 2.73$ & 24.6 & 0.060 \\
\hline Post 1 & $24.73 \pm 3.32$ & 23.7 & $25.53 \pm 2.37$ & 25.3 & 0.056 \\
\hline Post 24 & $25.74 \pm 3.39$ & 24.6 & $27.10 \pm 2.79$ & 27.0 & 0.095 \\
\hline$P$-value & \multicolumn{2}{|c|}{0.001} & \multicolumn{2}{|c|}{$<0.001$} & \\
\hline \multicolumn{6}{|l|}{$\mathrm{TT}:$} \\
\hline Pre & $20.10 \pm 1.53$ & 20.1 & $20.45 \pm 1.94$ & 20.2 & 0.416 \\
\hline Post 1 & $18.07 \pm 0.93$ & 18.1 & $17.96 \pm 1.28$ & 17.9 & 0.713 \\
\hline Post 24 & $16.48 \pm 1.35$ & 16.3 & $16.28 \pm 0.94$ & 16.2 & 0.535 \\
\hline$P$-value & \multicolumn{2}{|c|}{$<0.001$} & \multicolumn{2}{|c|}{$<0.001$} & \\
\hline \multicolumn{6}{|l|}{$F:$} \\
\hline Pre & $251.33 \pm 73.77$ & 253 & $258.20 \pm 64.62$ & 261 & 0.702 \\
\hline Post 1 & $302.28 \pm 72.18$ & 282 & $326.12 \pm 69.56$ & 321 & 0.905 \\
\hline Post 24 & $372.19 \pm 66.55$ & 372 & $435.53 \pm 91.04$ & 415 & $<0.003$ \\
\hline$P$-value & \multicolumn{2}{|c|}{$<0.001$} & \multicolumn{2}{|c|}{$<0.001$} & \\
\hline \multicolumn{6}{|l|}{$D:$} \\
\hline Pre & $0.32 \pm 0.08$ & 0.3 & $0.34 \pm 0.10$ & 0.3 & 0.590 \\
\hline Post 1 & $0.57 \pm 0.20$ & 0.6 & $1.03 \pm 0.65$ & 0.8 & $<0.001$ \\
\hline Post 24 & $0.91 \pm 0.31$ & 0.9 & $1.69 \pm 0.89$ & 1.4 & $<0.001$ \\
\hline$P$-value & \multicolumn{2}{|c|}{$<0.001$} & \multicolumn{2}{|c|}{$<0.001$} & \\
\hline \multicolumn{6}{|l|}{ INR: } \\
\hline Pre & $0.99 \pm 0.06$ & 1 & $0.98 \pm 0.19$ & 1 & 0.203 \\
\hline Post 1 & $1.01 \pm 0.04$ & 1 & $1.06 \pm 0.06$ & 1.1 & 0.001 \\
\hline Post 24 & $1.04 \pm 0.07$ & 1.1 & $1.12 \pm 0.07$ & 1.1 & $<0.001$ \\
\hline$P$-value & \multicolumn{2}{|c|}{$<0.001$} & \multicolumn{2}{|c|}{$<0.001$} & \\
\hline
\end{tabular}

PT - prothrombin time, aPTT - activated partial thromboplastin time, TT - thrombin time, INR - international normalized ratio, pre - preoperative, post 1 postoperative $1^{\text {st }} h$, post 24 - postoperative $24^{\text {th }} h$.

with normal liver function during anesthesia and surgery despite the presence of decreased LBF. However, patients with pre-existing liver disease should be prevented from having major decreases in $\operatorname{LBF}[26]$.
Epidural anesthesia produces a central sympathetic blockade that has strong effects on macro and microcirculation by reducing autonomic effects and modifying the endocrine profile [14]. The key mechanism of protective and supportive effects of 


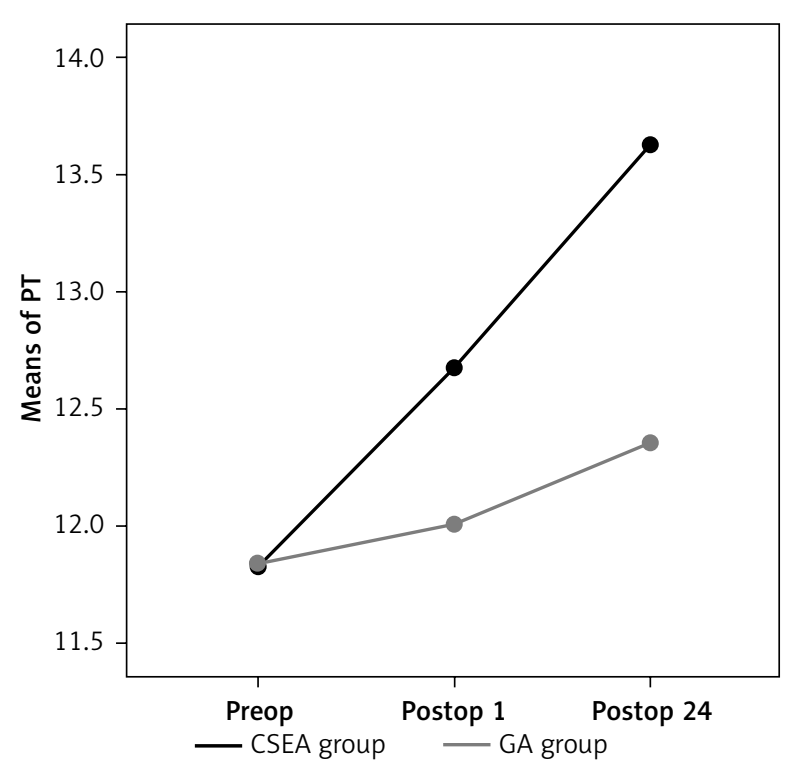

Figure 2. Prothrombin time values

PT - prothrombin time, preop - preoperative, postop 1 - postoperative $1^{\text {st }} h$, postop 24 - postoperative $24^{\text {th }} h$.

epidural anesthesia is suspected to be sympathetic block [27].

Khairy et al. evaluated other studies including coagulation and fibrinolysis parameters in venous blood samples taken from the upper and lower limbs of 25 patients who underwent LC because of

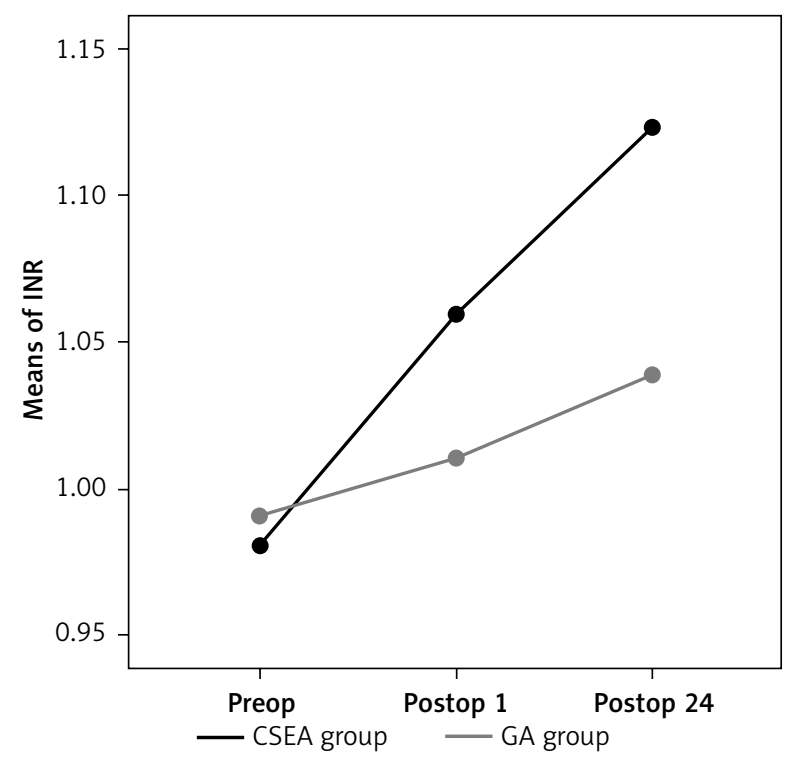

Figure 3. International normalized ratio values INR-international normalized ratio, preop-preoperative, postop 1 - postoperative $1^{\text {st }} h$, postop 24 - postoperative $24^{\text {th }} h$.
Table III. Comparison of laboratory values between GA and CSEA groups - II

\begin{tabular}{|lcc|}
\hline Parameter & $\begin{array}{c}\text { GA group } \\
(n=30)\end{array}$ & $\begin{array}{c}\text { CSEA group } \\
(n=30)\end{array}$ \\
\cline { 2 - 3 } & $P$-value & $P$-value \\
\hline PT Post 1-PT Pre & $<0.001^{*}$ & $<0.001$ \\
\hline PT Post 24-PT Post 1 & $0.005^{*}$ & $<0.001$ \\
\hline APTT Post 1-APTT Pre & $<0.001$ & 0.025 \\
\hline APTT Post 24-APTT Post 1 & $<0.001$ & 0.011 \\
\hline TT Post 1-TT Pre & $<0.001$ & $<0.001$ \\
\hline TT Post 24-TT Post 1 & $<0.001$ & $<0.001$ \\
\hline F Post 1-F Pre & $<0.001$ & $<0.001$ \\
\hline F Post 24-F Post 1 & $<0.001$ & $<0.001$ \\
\hline D Post 1-D Pre & $<0.001$ & $<0.001$ \\
\hline D Post 24-D Post 1 & $<0.001$ & $<0.001$ \\
\hline INR Post 1-INR Pre & 0.001 & $<0.001$ \\
\hline INR Post 24-INR Post 1 & $<0.001$ & 0.001 \\
\hline
\end{tabular}

${ }^{*}$ Parametric test. All other analyses Bonferroni correction $p<0.025$.

uncomplicated cholelithiasis [8]. The measurements of coagulation tests (PT, aPTT, and TT) were maintained at the same levels that had been noted in preoperative samples except for fibrinogen. These

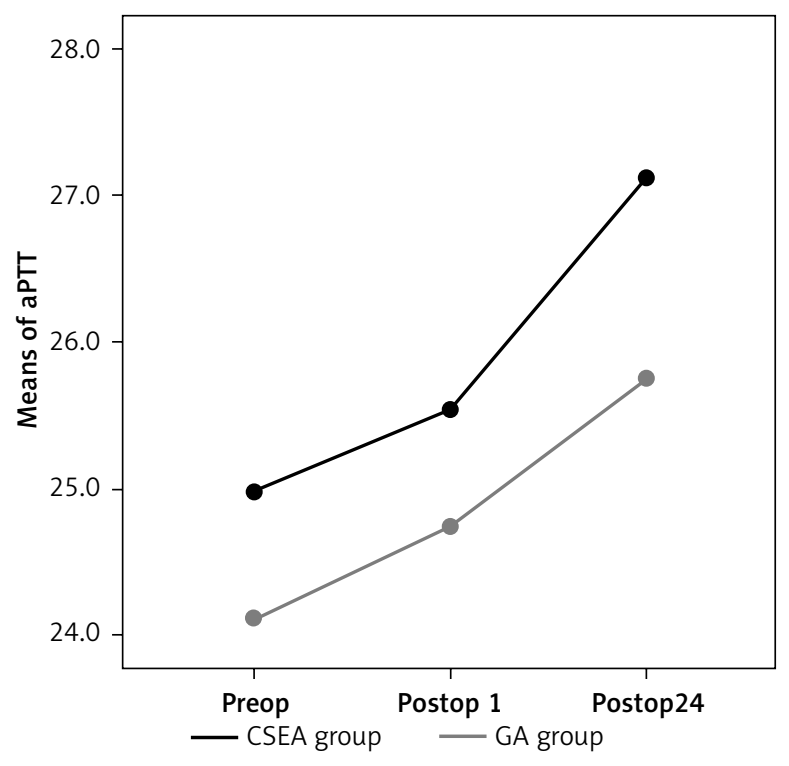

Figure 4. Activated partial thromboplastin time values

aPTT - activated partial thromboplastin time, preop-preoperative, postop 1 -postoperative $1^{\text {st }} h$, postop 24 - postoperative $24^{\text {th }} h$. 


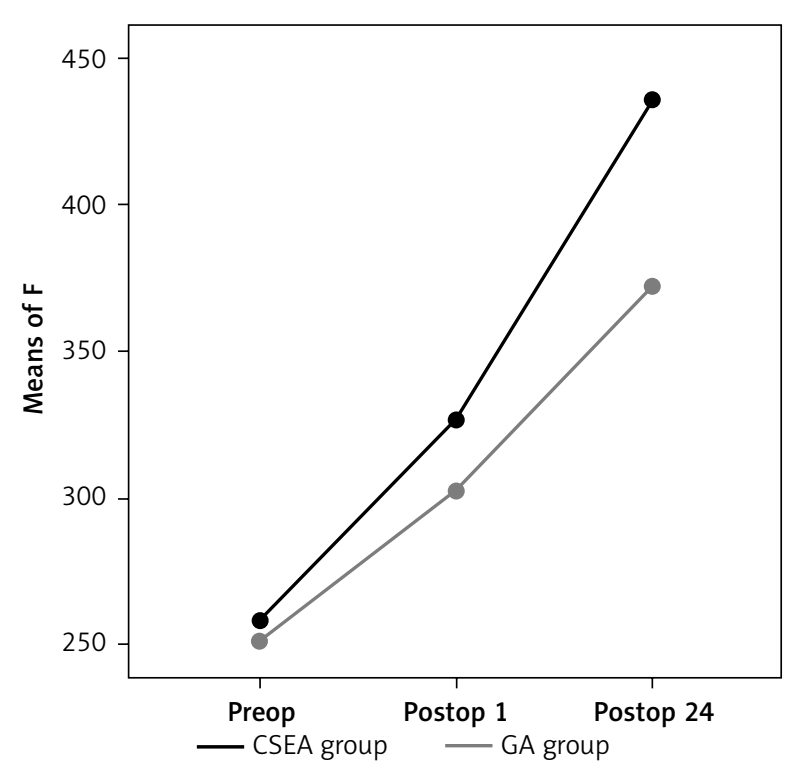

Figure 5. Fibrinogen values

$F$-fibrinogen, preop - preoperative, postop 1 - postoperative $1^{\text {st }} h$, postop 24 - postoperative $24^{\text {th }} \mathrm{h}$.

rose significantly $24 \mathrm{~h}$ after surgical intervention. Moreover, AT values decreased slightly immediately following surgical intervention, but they increased to preoperative levels $24 \mathrm{~h}$ following surgery. There were no significant fluctuations in other coagulation inhibitors (total and free protein $\mathrm{S}$, and protein $\mathrm{C}$ ) and fibrinolytic parameters [8].

Trepenaitis et al. evaluated 50 patients with major upper abdominal procedure (cancer of papilla of Vater, pancreatic cancer, chronic pancreatitis, and stomach cancer) [28]. They combined GA and thoracic epidural anesthesia in the study group and did not add the thoracic epidural anesthesia in the control group when evaluating hepatic blood flow. They reported that epidural anesthesia decreased hepatic blood flow [28]. Both experimental and clinical studies showed increased intra-abdominal pressure created during pneumoperitoneum, decreased hepatic microcirculation, and lower portal and renal blood flow [3, 29]. Takagi found that an increase of intraperitoneal pressure over $10 \mathrm{~mm} \mathrm{Hg}$ resulted in a significant decrease both in blood flow and diameter of the portal vein [29]. Jakimowitcz et al. observed that the portal blood flow decreased to a rate of $56 \mathrm{ml} / \mathrm{min}$ during pneumoperitoneum using $14 \mathrm{~mm} \mathrm{Hg}$. This was $56 \%$ of the baseline flow at the beginning [30].

Donmez et al. compared the effects of coagulation and fibrinolysis of LC carried out with $10 \mathrm{~mm} \mathrm{Hg}$

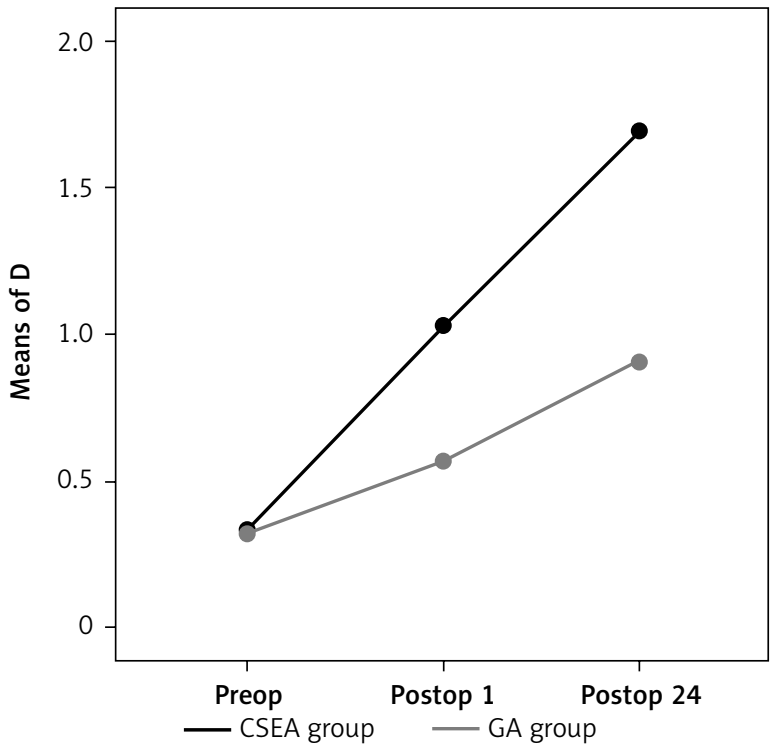

Figure 6. D-dimer values

$D$ - D-dimer, preop - preoperative, postop 1 - postoperative $1^{\text {st }} h$, postop 24 - postoperative $24^{\text {th }} \mathrm{h}$.

and $14 \mathrm{~mm} \mathrm{Hg}$ pneumoperitoneum. They found that pneumoperitoneum caused significantly high levels of PT, aPTT, INR, D-dimer and fibrinogen values at both pressure levels [2]. They also observed in the same study that D-dimer values significantly increased under pneumoperitoneum with high pressure [2]. We planned the $\mathrm{CO}_{2}$ pneumoperitoneum pressure to be $10 \mathrm{~mm} \mathrm{Hg}$ because of these previous reasons, and we planned to minimize the possible effect of reperfusion damage.

The tendency to hypercoagulability followed by a decrease in fibrinolysis activity in the hemostasis mechanism can be encountered after surgical trauma. Thromboembolic risks increase with those changes in hemostasis mechanism [19]. Despite PP, laparoscopic surgery has lower thromboembolic risks compared to open surgery [3, 20, 31, 32]. Half of the postoperatively diagnosed DVT occurs during the surgical intervention itself. There is a significant venous stasis related to the decreased muscle tone under general anesthesia [25]. Lindberg et al. found that the total pulmonary embolism was $0.06 \%$, and that the average rate of reported deep vein thrombosis was $0.03 \%$ in a literature review of thromboembolic complications after LC [17].

The mean age in group 1 was $50.7 \pm 16.2$ (19-77) years, while it was $52.4 \pm 17.6(22-79)$ years in group 2 $(p=0.723)$. The mean operation time (MOT) was 
$53.6 \pm 8.7(45-80) \mathrm{min}$ in group 1, but it was 63.9 $\pm 10.2(53-92) \mathrm{min}$ in group $2(p<0.001)$. There was no significant difference in PP duration between the two groups. The difference in MOT between the two groups was attributed to the long duration of CSEA preparation and application. The difference was because of the waiting period of 20 min for patients in group 2 at the beginning of the effect of epidural anesthesia. There were no significant differences between the two groups in terms of gender, age, ASA classification, use of any drain, complications, concomitant diseases, weight, height, or time to first postoperative oral intake.

Decreased PT shows a tendency toward hypercoagulopathy [21]. Ntourakis et al. compared the coagulation and fibrinolysis factors preoperatively and $24 \mathrm{~h}$ postoperatively in a series consisting of $119 \mathrm{pa}$ tients who underwent LC under GA [33]. They detected significant differences in PT values between preoperative and postoperative samples, and this difference was attributed to changes in hepatic function in addition to changes in the blood flow in the portal vein due to PP during LC [33]. Similarly, postoperative PT levels in our study increased relative to preoperative levels in both groups 1 and 2 . The significant increase in the PT of group 2 compared to group 1 was suggestive of CSEA augmenting the effect. The PT in group 2 increased more and showed that spinal epidural anesthesia caused more vasodilation in the periphery and had a bigger impact on hepatic perfusion compared to general anesthesia.

Similar changes were seen for INR values along with the PT values in both groups. This supported our finding that the LC decreased the coagulopathy tendency, and CSEA augments it. Our findings can also be attributed to changes in the blood flow in the portal vein due to PP and to changes in hepatic functions. While shorter PT values are expected with older age, there are reports showing high values of D-dimer, PT and INR in elderly people [33]. Nonetheless, the FDP and D-dimer values were significantly higher in older patients postoperatively [33].

The aPTT is a direct measurement of coagulation. A short aPTT shows activation of coagulation [21]. Short aPTT values following surgical intervention indicate hypercoagulability [20]. We found a significant increase in aPTT values 1 and $24 \mathrm{~h}$ postoperatively compared to baseline in group 1 . We also found a significant increase in the aPTT values at $24 \mathrm{~h}$ postoperatively compared to the mean base- line values in group 2. When the two groups were compared, the aPTT values were significantly higher preoperatively and 1 and $24 \mathrm{~h}$ postoperatively in group 2.

Both groups had a significant increase in thrombin time (TT) values at 1 and $24 \mathrm{~h}$ versus baseline. The TT predicts the cascade of coagulation and anticoagulation and reflects the fibrinolytic system. Therefore, we assumed that post-operative thrombosis might have a significant correlation with TT. The decrease in TT might be related to the increase of fibrinogen levels, which can show hypercoagulability that supports the thrombotic tendency. We found that the decrease in TT was significantly higher in group 2 compared to group 1.

Fibrinogen is produced in the liver as an acute phase protein. The enzymatic activation of thrombin transforms fibrinogen into fibrin [32, 34, 35]. Fibrinogen (F) is also known as coagulation factor I and is the principal protein in coagulation. Schietroma et al. reported that $F$ values increased postoperatively and reached a maximum $72 \mathrm{~h}$ after surgery [34].

Increased levels of fibrinogen are associated with hypercoagulability [33]. The level of fibrinogen is positively correlated with factors such as resting blood pressure, stress, BMI, tobacco, and age [33]. Both premenopausal and postmenopausal women, and men of all ages, are similar in terms of the magnitude of hemostatic factors. Despite the periodic variations in factor VII, fibrinogen, and PAI-1 during menstruation in premenopausal women, these results do not differ between postmenopausal women and men of any age [36].

The $F$ values were significantly higher in group 2 than group 1 at all time points. The PP pressure was constant, and the higher increase in values in group 2 showed the effect of spinal epidural anesthesia on hepatic perfusion and its relevance to vasodilatation in peripheral vessels. The increase in $F$ in group 2 was within the normal range compared to group 1. Thus, it increased hypercoagulopathy.

D-dimer (DD) levels can be encountered in secondary fibrinolysis, venous thrombosis, and pulmonary emboli. There is a link between DD and fibrin degradation products (FDP) formed by fibrin. Milic et al. reported that D-dimer was the only reliable and sensitive marker for coagulation and fibrinolysis [37]. They also emphasized that other markers such as PT and aPTT were indirect indicators for coagulation and fibrinolysis [37]. Activation of fibrinolysis 
can counteract the increase in coagulation, and the increase in DD found in our study indicates that this may be the case [21]. The DD measurements are widely used in clinical practice and have become one of the most valuable indicators to diagnose and monitor thrombotic disorders and disseminated intravascular coagulation (DIC) [38]. These data confirm the activation of both coagulation and fibrinolytic systems postoperatively. It is obvious that there was an imbalance between coagulation and fibrinolysis because the coagulation function was stronger than the fibrinolytic system. The post-operative DD levels significantly increased in both groups compared to baseline. The DD values at 1 and $24 \mathrm{~h}$ were significantly higher in group 2 than in group 1. The higher increase in group 2 was probably due to the effect of spinal epidural anesthesia on hepatic perfusion and stasis due to peripheral vasodilatation. The increase in hypercoagulopathy and fibrinolysis in group 2 seriously increased the DVT risk. Thus, we aimed to minimize the effects of PP on coagulation and fibrinolysis by performing $\mathrm{LC}$ at $10 \mathrm{~mm} \mathrm{Hg} \mathrm{CO}$ pressure in our patients.

\section{Conclusions}

In our study, the anesthesia technique affected coagulation and fibrinolysis parameters independent of PP. While values of PT, aPTT, and INR were found to be high following LC-supported hypocoagulability, increased DD promoted an increase in fibrinolysis in both groups. Shorter TT and higher fibrinogen values may indicate hypercoagulability. Coagulation and fibrinolysis parameters showed changes in LC. When PP is constant, the levels of F, DD, PT, APTT, and INR are higher in the spinal anesthesia group both within the group and compared to the general anesthesia group. There is a spike in TT levels after spinal epidural, and this promotes hypercoagulopathy. Thus, spinal epidural anesthesia increases hypercoagulability much more than general anesthesia. Thus, the risk of thrombosis and emboli increases in LC especially when it is performed under CSEA. We believe that anti-thromboembolic prophylaxis is necessary in laparoscopic interventions especially in elderly patients for whom cardiac rhythm disturbances and increased stasis within the venous system might contribute to an increased risk of thrombosis and emboli. One weakness of our study was the small number of patients. Thus, a more comprehensive randomized clinical study is needed with more cases.

\section{Conflict of interest}

The authors declare no conflict of interest.

\section{References}

1. Amin B, Chengcai Z, Wei Y, et al. Effects of pneumoperitoneum of laparoscopic cholecystectomy on the coagulation system of patients. A prospective observational study. Chin Med J 2014; 127: 2599-604.

2. Donmez T, Uzman S, Yıldırım D, et al. Is there any effect of pneumoperitoneum pressure on coagulation and fibrinolysis during laparoscopic cholecystectomy? Peer J 2016; 4: e2375.

3. Prisci D, De Gaudio AR, Carla R, et al. Videolaparoscopic cholecystectomy induces a hemostasis activation of lower grade than does open surgery. Surg Endosc 2000; 14: 170-4.

4. Mehta N, Dar MR, Sharma S, et al. Thoracic combined spinal epidural anesthesia for laparoscopic cholecystectomy. A feasibility study. J Anaesthesiol Clin Pharmacol 2016; 32: 224-8.

5. Imbelloni LE, Fornasari M, Fialho JC, et al. General anesthesia versus spinal anesthesia for laparoscopic cholecystectomy. Rev Bras Anestesiol 2010; 60: 217-27.

6. Kalaivani V, Vinayak SP, Sreevathsa MR, et al. Laparoscopic cholecystectomy under spinal anesthesia vs. general anesthesia. A prospective randomised study. J Clin Diagn Res 2014; 8: NC01-4

7. Singh CRK, Saini AM, Goel N, et al. Major laparoscopic surgery under regional anesthesia. A prospective feasibility study. Med J Armed Forces India 2015; 71: 126-31.

8. Khairy G, Ghumlas AA, Dohayan AA, Gader AG. Haemostatic changes in laparoscopic cholecystectomy: a comparison between upper and lower limb measurements. Surg Laparosc Endosc Percutan Tech 2010; 20: 79-83.

9. Ellekany M. Comparative study between general and thoracic spinal anesthesia for laparoscopic cholecystectomy. Egypt J Anesth 2013; 29: 375-81.

10. Makwana DS, Patil PN, Cercetta CS, et al. A comparison of EtCO2 and $\mathrm{PaCO} 2$ in laparoscopic surgery during general anesthesia. GCSMC J Med Sci 2014; 3: 12-5.

11. Lee JH, Huh J, Kim DK, et al. Laparoscopic cholecystectomy under epidural anesthesia, a clinical feasibility study. Korean J Anesthesiol 2010; 59: 383-8.

12. Donmez T, Erdem VM, Uzman S, et al. Laparoscopic cholecystectomy under spinal-epidural anesthesia vs. general anesthesia: a prospective randomised study. Ann Surg Treat Res 2017; 92: $136-42$

13. Duncan CB, Riall TS. Evidence-based current surgical practice, calculous gallbladder disease. J Gastrointest Surg 2012; 16 : 2011-25.

14. Siniscalchi A, Gamberini L, Laici C, et al. Thoracic epidural anesthesia, effects on splanchnic circulation and implications in anesthesia and Intensive care. World J Crit Care Med 2015; 4: 89-104. 
15. Tiwari S, Chauhan A, Chaterjee P, Alam MT. Laparoscopic cholecystectomy under spinal anesthesia. A prospective, randomised study. J Minim Access Surg 2013; 9: 65-71.

16. Hajong R, Khariong PDS, Baruah AJ, et al. Laparoscopic cholecystectomy under epidural anesthesia, a feasibility study. N Am J Med Sci 2014; 6: 566-9.

17. Lindberg F, Bergqvist D, Rasmussen I. Incidence of thromboembolic complications after laparoscopic cholecystectomy review of the literature. Surg Laparosc Endosc 1997; 7: 324-31.

18. Vecchio R, Cacciola E, Di Martino M, et al. Modifications of coagulation and fibrinolytic parameters in LC. Surg Endosc 2003 17: 428-33.

19. Geerts WH, Bergqvist D, Pineo GF, et al. Prevention of venous thromboembolism: American College of Chest Physicians evidence-based clinical practice guidelines. Chest 2008; 133 381S-453S

20. Caprini JA, Arcelus JI, Laubach M, et al. Postoperative hypercoagulability and deep-vein thrombosis after laparoscopic cholecystectomy. Surg Endosc 1995; 9: 304-9.

21. Garg PK, Teckchandani N, Hadke NS, et al. Alteration in coagulation profile and incidence of DVT in laparoscopic cholecystectomy. Int J Surg 2009; 7: 130-5.

22. Veekash G, Wei LX, Su M. Carbon dioxide pneumoperitoneum, physiologic changes and anesthetic concerns. Ambulatory Surgery 2010; 12: 41-6.

23. Liu Q, Zhang G, Zhong Y, et al. Meta-analysis of the clinical application on gasless laparoscopic cholecystectomy in China. Int J Clin Exp Med 2015; 8: 1684-90.

24. Amir S, Weinbroum AA. Carbon dioxide pneumoperitoneum-related liver injury is pressure dependent. A study in an isolated-perfused organ model. Surg Endosc 2008; 22: 365-71.

25. Wazz G, Branicki F, Taji H, Chishty I. Influence of pneumoperitoneum on the deep venous system during laparoscopy. JSLS 2000; 4: 291-5.

26. Strunin L, Davies JM. The liver and anesthesia. Can Anaesth Soc 1983; 30: 208-17

27. Rahimzadeh P, Safari S, Faiz SHR, Alavian SM. Anesthesia for patients with liver disease. Hepat Mon 2014; 14: e19881.

28. Trepenaitis D, Pundzius J, Macas A. The influence of thoracic epidural anesthesia on liver hemodynamics in patients under general anesthesia. Medicina (Kaunas) 2010; 46: 465-71.

29. Takagi S. Hepatic and portal vein blood flow during carbon dioxide pneumoperitoneum for laparoscopic hepatectomy. Surg Endosc 1998; 12: 427-31.

30. Jakimowicz J, Stultiëns G, Smulders F. Laparoscopic insufflation of the abdomen reduces portal venous flow. Surg Endosc 1998; 12: $129-32$.

31. Marakis G, Pavlidis TE, Ballas K, et al. Changes in coagulation and fibrinolysis during laparoscopic cholecystectomy. J Laparoendosc Adv Surg Tech A 2006; 16: 582-6.

32. Diamantis T, Tsiminikakis N, Skordylaki A, et al. Alterations of hemostasis after laparoscopic and open surgery. Hematology 2007; 12: 561-70.

33. Ntourakis D, Sergentanis TN, Georgiopoulos J, et al. Subclinica activation of coagulation and fibrinolysis in laparoscopic cholecystectomy: do risk factors exist? Int J Surg 2011; 9: 374-7.

34. Schietroma M, Carlei F, Mownah A, et al. Changes in the blood coagulation, fibrinolysis, and cytokine profile during lapa- roscopic and open cholecystectomy. Surg Endosc 2004; 18: 1090-6.

35. Frantzides C, Welle SN, Ruff TM, Frantzides AT. Routine anticoagulation for venous thromboembolism prevention following laparoscopic gastric bypass. JSLS 2012; 16: 33-7.

36. Hill AM, Stewart PW, Fung MK, et al. Monthly hemostatic factor variability in women and men. Eur J Clin Invest 2014; 44: 309-18.

37. Milic DJ, Pejcic VD, Zivic SS, et al. Coagulation status and the presence of postoperative deep vein thrombosis in patients undergoing laparoscopic cholecystectomy. Surg Endosc 2007; 21: 1588-92

38. Buhe A, Chengcai Z, Wei Y, et al. Effects of pneumoperitoneum of laparoscopic cholecystectomy on the coagulation system of patients: a prospective observational study. Chin Med J 2014; 127: 2599-604.

Received: 23.05.2017, accepted: 20.08.2017. 